\title{
Effects of the 2018 Japan Floods on long- term care insurance costs in Japan: retrospective cohort study
}

\author{
Shuhei Yoshida ${ }^{1 *}$, Saori Kashima², Shinya Ishii ${ }^{3}$, Soichi Koike ${ }^{4}$ and Masatoshi Matsumoto ${ }^{1}$
}

\begin{abstract}
Background: Climate change has increased the frequency and severity of torrential rains and floods around the world. Estimating the costs of these disasters is one of the five global research priorities identified by WHO. The 2018 Japan Floods hit western Japan causing extensive destruction and many deaths, especially among vulnerable elderly. Such affected elderly would need long-term care due to the various health problems caused by the disaster. A LongTerm Care Insurance (LTCI) system provides care services in Japan. The aim of this study was to evaluate the effect of the 2018 Japan Floods on LTCl costs and service utilization.

Methods: The participants of this retrospective cohort study were all verified persons utilizing LTCI services in Hiroshima, Okayama and Ehime prefectures. The observation period was from 2 months before to 6 months after the disaster. We used Generalized Estimating Equations (GEEs) to examine the association between disaster status (victims or non-victims) and the monthly total costs of LTCI service (with gamma-distribution/log-link) by residential environment (home or facility). Among home residents, we also examined each service utilization (home-based service, short-stay service and facility service), using the GEEs. After the GEEs, we estimated Average Marginal Effects (AME) over all observation periods by months as the attributable disaster effect.

Results: The total number of participants was 279,578. There were 3024 flood victims. The disaster was associated with significantly higher total costs. The AME for home residents at 2 months after was $\$ 214$ (Standard Error (SE): 12, $p<0.001$ ), which was the highest through the observation period. Among facility residents, the AME immediately after the disaster increased by up to $\$ 850$ (SE: 29, $p<0.001$ ). The service utilization among home residents showed a different trend for each service. The AME of home-based services decreased by up to $-15.2 \%$ (SE:1.3, $p<0.001)$. The AME for short-stay service increased by up to $8.2 \%$ (SE: $0.9, p<0.001$ ) and the AME for facility service increased by up to $7.4 \%$ (SE: 0.7, $p<0.001$ ), respectively.
\end{abstract}

Conclusions: The 2018 Japan Floods caused an increase in LTCl costs and the utilization of short-stay and facility services, and a decrease in utilization of home-based services.

Keywords: Climate change, Natural disaster, Disaster preparedness, Long-term care, Long-term care insurance service, Claim data, Rural health services

*Correspondence: yoshida.shuhei.0810@gmail.com

1 Department of Community-Based Medical System, Graduate School of Biomedical and Health Sciences, Hiroshima University, 1-2-3 Kasumi, Minami-ku, Hiroshima-ken, Hiroshima-shi 734-8551, Japan

Full list of author information is available at the end of the article

\section{Background}

Climate change is an inseparable factor affecting human health and wellbeing [1]. The World Health Organization (WHO) reported that climate change is expected to cause approximately 250,000 additional deaths per year 
between 2030 and 2050 [2]. Due to the effects of climate change, the frequency and magnitude of disasters caused by floods or torrential rains have increased in recent years around the world [3]. Estimating the costs of these climate change-related disasters is one of the five global research priorities identified by WHO [4].

In Japan, torrential rains have occurred every year in recent times, with the 2018 torrential rains and floods in western Japan being the largest so far $[5,6]$. Due to the severity of the storms, they became known as the 2018 Japan Floods (2018-nen-sitigatu-gou) by the Japan Meteorological Agency [7]. The enormous damage was reported as 237 dead, eight missing, 433 injured, and 6767 houses completely destroyed $[8,9]$. The disruption of transportation networks and utilities made it difficult to transport necessary emergency relief supplies [10]. The amount of damage caused by the 2018 Japan Floods was approximately US $\$ 9.86$ billion ( $(1158$ billion), which was the largest amount of damage ever caused by a single incidence of torrential rains or floods in Japan [11].

Natural disasters often cause not only direct disasterrelated deaths, but also post-disaster physical or mental problems [12-20]. Especially, disasters affect older people to a greater extent [21]. In the Great East Japan Earthquake (GEJE), most victims and deaths were among the elderly. Similarly, $90 \%$ of victims during the torrential rains were over 65 years of age [9]. Elderly victims often need long-term care as their health status becomes exacerbated [22]. Therefore, it is important to estimate the costs of long-term care caused by these disaster-related health problems.

To provide long-term care for the vulnerable elderly, the Japanese government established a public Long-Term Care Insurance (LTCI) system in 2000 [23-25]. The LTCI system provides necessary care services for the elderly. The main users of LTCI services are 65 years of age or older. The care services are broadly divided into three groups: 1) home-based services providing care while living at their private homes, 2) short-stay services that consist of respite care for a short period and 3) facility services that provide residence care to those who are unable to live at home $[23,26]$. Local governments administer the LTCI system. Japan has the highest rate for an aging population among the world and currently more than 5 million people have received LTCI certification [27]. Therefore, the LTCI system has become indispensable for Japanese social security [23].

Although the increase of disaster-related LTCI costs is an urgent issue in an aging society, few studies have examined the effect of disasters on LTCI costs. Community-based ecological studies showed changes in LTCI service after the GEJE [28-30]. However, there are no studies that examine the ever-changing effect of a disaster at the individual level chronologically and precisely. In addition, since the impact of the disaster from torrential rains and floods is different from an earthquake, the impact on LTCI service could be different [31]. For these reasons, it is highly important to examine the impact of the 2018 Japan Floods on LTCI costs.

In this study, we investigate the effect of the 2018 Japan Floods on LTCI cost for disaster victims. Based on the results, we examined the impact of torrential rains or floods, which are increasing due to climate change, on the costs of elderly long-term care and provide insights for other countries considering the introduction of a public LTCI system.

\section{Methods}

\section{Study design}

This study was a retrospective cohort study.

\section{LTCl system}

The utilization of LTCI services in Japan requires a certification of care-level. Elderly persons are certified after an application that they or their family submit. Subsequently, a care manager, a local official or other carerelated professional that is independent from applicants are asked by the local government to visit the applicant to evaluate their care needs by using a structured questionnaire (nintei-tyousa). The certification also requires a physician's written opinion (shujii-ikensyo), which is a care evaluation by a primary care physician. Next, a Care Need Certification Committee determines the care-level based on both evaluations. The care-levels are graded into 7 levels (support need levels 1-2 and care need levels 1-5). The higher the care-level, the higher the monthly limit for LTCI services. If the care needs change due to a disease or Activity of Daily Living (ADL), applicants can apply for a re-certification to change the care-level. The certification requiring support 1 , which is the lowest care-level, allows for the use of services up to about US\$455 $(\backslash 50,000)$ per month. The person certified as requiring long term care 5 , which is the highest care-level, can use LTCI services up to about US\$3257 $(\backslash 358,300)$ per month. Out-of-pocket expenditures for LTCI is from 10 to $30 \%$ according to income.

Various types of public or private residential facilities are involved in LTCI services. Each type of facility has a specific criterion for admission. Generally, a certain care-level is needed for admission to each facility. The daily basic cost for residential facility service is set per the facility type. Care for residents is provided within the basic cost. 


\section{Data source}

This study was conducted using a special sampling of certification data for long-term care and long-term care insurance claim data (Approval no. 0711-1). These data were stored in a long-term care insurance comprehensive database, which is managed by the Ministry of Health, Labour and Welfare (MHLW). This database collects digitized claims of LTCI that are summarized monthly with details for all services used by each user. This database also includes age classification, gender and other characteristics of users concerning long-term care insurance. The MHLW has provided datasets extracted from this database for research institutes since 2018, with the permission of an expert council. Researchers can apply for its use through the MHLW website and are allowed to use the data after meeting security systems such as limiting the member of data users [32].

If a LTCI user interrupts service use during a month due to any reason, such as hospitalization, death or change of needs, the cost for LTCI service does not accrue. The reasons are not included in this database.

\section{Setting}

The setting was Hiroshima, Okayama and Ehime prefectures (Fig. 1). These prefectures accounted for 212 out of 237 deaths, 8 out of 8 missing, 6603 out of 6767 houses completely destroyed and 10,012 out of 11,243 houses partially destroyed [9]. Because of the concentration of the damage, we choose these locales as the study setting.

\section{Participants}

The participants were all LTCI service users in Hiroshima, Okayama and Ehime prefectures during May 2018 ( 2 months before 2018 Japan Floods). There were 368,778 certified people in these prefectures regardless of the service utilization of LTCI [33]. The observation period was from May 2018 to December 2018 (6 months after 2018 Japan Floods).

\section{Disaster status}

We defined victims as participants whose monthly cost for LTCI services changed to exempt after the disaster. This conformed with the announcement of MHLW that all victims of this disaster were exempt from LTCI service costs, even if they used LTCI services in another region from their registered home region [34]. Local governments also authorized a designation as victim when a person's house was completely or partially damaged, burned down, or flooding of a floor, or similar damage, when a main breadwinner died, the breadwinner was seriously injured or became ill, or the breadwinner went missing. Only 10 people were exempted for the LTCI service cost until the year before the disaster [35]. Because this exemption excluded those who paid no outof-pocket expenditures for the LTCI service cost, such as
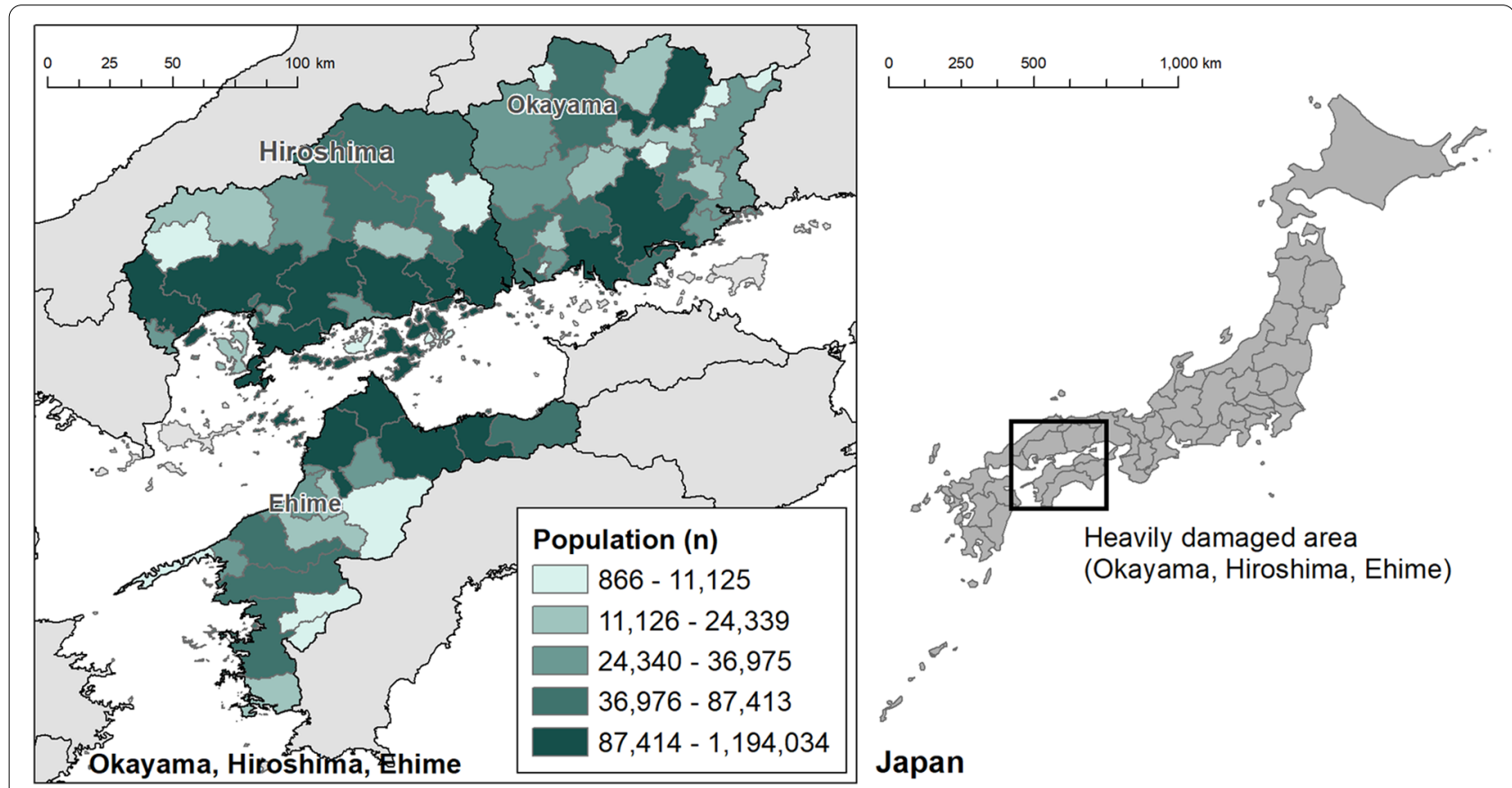

Fig. 1 Population by municipality. Footnote: Population data was obtained from Statistical Observations of Municipalities 2020 published by the Ministry of Internal Affairs and Communications 
welfare recipients and A-bomb survivors, we could not detect their impact by the disaster.

\section{Covariates}

We extracted the monthly total costs for LTCI services and the monthly utilization of each LTCI service type, disaster status (victims or non-victims), age classification, gender, care-level, residential environment (home residents or facility residents) and facility transfer. The monthly total costs for LTCI services were based on the amount of service which a participant used in a month. We converted Japanese yen to US dollars using the average rate for $2018(\$ 1=\backslash 110)$ [36]. The LTCI service type was defined by Service Classification Code (servicekubun-code) and classified into three types: home-based service, short-stay service, and facility service (Supplementary Table 1 shows this in more detail [see Supplementary File 1]). We determined the utilization of each LTCI service type by the accrual of claim data. We defined home residents as users who did not use a facility service on the first month of the observation period ( 2 months before the disaster). For facility residents, a change in the facility code or the service classification code after the disaster was judged as a facility transfer.

\section{Statistical analysis}

We described the baseline characteristics of victims and non-victims. Chi-square test was used for the discrete variables. Wilcoxon's rank sum test was performed for ordinal variables and for continuous variables without a normal distribution.

We used Generalized Estimating Equations (GEEs) to examine the association between disaster status and the costs of LTCI service. The dependent variables were the monthly total LTCI costs by home residents and facility residents. Since our primary interest was the monthly change due to the disaster, we added the interaction term between disaster status and month along with disaster status, month, age classification, gender and carelevel as covariates. The GEE models were specified with a Gamma distribution and a log-linked function, because cost data usually skewed to the right. This model has been proven to be appropriate for analyzing cost data [37]. This approach was applied to the past studies when estimating costs [38-40]. However, a large proportion of zeros ( $20 \%$ or more) can cause inadequate estimation [18]. After we confirmed that the proportion of zeros by each month was less than $20 \%$, we applied these GEE models.

The costs for facility residents are calculated comprehensively for all care provided in the facility. Meanwhile, the costs for home residents are calculated by adding various home-based services and short-stay services.
Furthermore, home residents could move into facilities during the observation period. Therefore, we also examined the association service utilization among home residents and disaster status, using GEEs with the same covariates. When the incidence of an outcome is over $10 \%$, the adjusted odds ratio derived from the logistic regression overestimates the risk ratio [41]. Because the incidence of service utilization is common $(>10 \%)$, the GEE models were specified with a Poisson distribution, a log-linked function and robust error variances $[42,43]$. These modified Poisson models are robust when estimating relative risks or risk ratios for common binary outcomes [44]. Because the utilization of facility service did not accrue for the first month of the observation period ( 2 months before the disaster) as per our definition, we examined the utilization from 1 month before to 6 months after the disaster. Home-based service and short-stay service were examined through all observation periods. Because the incidence of outcomes is common ( $>10 \%)$, the GEE models were specified with a Poisson distribution, a log-linked function and robust error variances [42, 43].

In the GEE models, we took into account correlations among individuals using exchangeable correlation structures. After conducting the GEEs, we used these models to estimate the disaster attributable impact by each month as Average Marginal Effects (AME). AME were estimated to assess the impacts on LTCI costs and the probability of LTCI service utilization associated with changes in disaster status, keeping all of the other covariates fixed.

We performed all statistical analyses using STATA/MP version 16 (StataCorp, 2019).

\section{Results}

The total number of participants was 279,578. Victims, whose monthly cost for LTCI services changed to exempt after the disaster, accounted for $1.1 \%$ of the total $(n=3024)$.

Participant characteristics are shown in Table 1. The proportion of males was under $30 \%$ in both groups. The care-level of victims was lower than non-victims by Wilcoxon's rank sum test $(p<0.001)$. Participants whose care-level changed during the observation period were $18.3 \%$ in victims $(n=550)$ and $15.1 \%$ in non-victims, respectively. This was statistically significant by chisquare test $(p<0.001)$. The proportion of facility residents at 2 months before the disaster was $22.2 \%(n=672)$ in victims and $30.3 \%(n=83,795)$ in non-victims. Participants who did not use LTCI services for an entire month during the observation period was $26.7 \%(n=808)$ in victims and $16.0 \%(n=44,181)$ in non-victims $(p<0.001)$. Among home residents, the total service cost of victims 
Table 1 Demographic Characteristics

\begin{tabular}{|c|c|c|c|c|c|}
\hline & \multicolumn{2}{|c|}{ Victims of the disaster } & \multicolumn{2}{|c|}{ Non-victims of the disaster } & \multirow[t]{2}{*}{$p$ value } \\
\hline & $n=3024$ & $1.1 \%$ & $n=276,554$ & $98.9 \%$ & \\
\hline \multicolumn{6}{|l|}{ Age, no. (\%) } \\
\hline under 65 & 59 & 2.0 & 5696 & 2.1 & \multirow[t]{4}{*}{$0.02^{*}$} \\
\hline $65-74$ & 314 & 10.4 & 26,908 & 9.7 & \\
\hline $75-84$ & 1012 & 33.5 & 86,869 & 31.4 & \\
\hline over 85 & 1639 & 54.2 & 157,081 & 56.8 & \\
\hline \multicolumn{6}{|l|}{ Gender, no. (\%) } \\
\hline Male & 897 & 29.7 & 77,738 & 28.1 & \multirow[t]{3}{*}{$0.075^{*}$} \\
\hline Female & 2073 & 68.6 & 192,987 & 69.8 & \\
\hline Missing ${ }^{+}$ & 54 & 1.8 & 5829 & 2.1 & \\
\hline \multicolumn{6}{|c|}{ Level of long-term care need, no. (\%) } \\
\hline Support need level $1 \neq$ & 299 & 9.9 & 21,555 & 7.8 & \multirow[t]{7}{*}{$<0.001 \dagger$} \\
\hline Support need level 2 & 398 & 13.2 & 28,387 & 10.3 & \\
\hline Care need level 1 & 727 & 24.0 & 61,979 & 22.4 & \\
\hline Care need level 2 & 584 & 19.3 & 54,551 & 19.7 & \\
\hline Care need level 3 & 398 & 13.2 & 42,414 & 15.3 & \\
\hline Care need level 4 & 342 & 11.3 & 37,282 & 13.5 & \\
\hline Care need level 5 & 276 & 9.1 & 30,285 & 11.0 & \\
\hline \multicolumn{6}{|c|}{ Change in the level of long-term care need at December, no. (\%) } \\
\hline Increased & 376 & 12.4 & 29,074 & 10.5 & \multirow[t]{4}{*}{$<0.001^{*}$} \\
\hline $\begin{array}{l}\text { Unchanged (without re-certifi- } \\
\text { cation) }\end{array}$ & $2047(1881)$ & $67.7(62.2)$ & $202,166(155,845)$ & $73.1(56.4)$ & \\
\hline Decreased & 174 & 5.8 & 12,647 & 4.6 & \\
\hline Missing§ & 427 & 14.1 & 32,667 & 11.8 & \\
\hline Facility residents, no (\%) & 672 & 22.2 & 83,795 & 30.3 & $<0.001^{*}$ \\
\hline Facility transfer, no (\%) & 247 & 36.7 & 3028 & 3.6 & $<0.001^{*}$ \\
\hline \multicolumn{6}{|c|}{ Existence of a total disused month of LTCI service, no (\%) } \\
\hline All period & 808 & 26.7 & 44,181 & 16.0 & $<0.001^{*}$ \\
\hline \multicolumn{6}{|l|}{ Month } \\
\hline $1-3$ & 502 & 16.6 & 24,940 & 9.0 & $<0.001^{*}$ \\
\hline $4-6$ & 564 & 18.7 & 37,217 & 13.5 & $<0.001^{*}$ \\
\hline \multicolumn{6}{|l|}{ Cost of per month, mean (SD) } \\
\hline Home residents & 1029 & 1029 & 1002 & 832 & $<0.001 \dagger$ \\
\hline Facility residents & 2404 & 1219 & 2115 & 850 & $<0.001 \dagger$ \\
\hline \multicolumn{6}{|c|}{ Mean of LTCI service utilizations among home residents per month, no (\%) } \\
\hline Home-based service & 1399 & 59.5 & 137,956 & 71.6 & $<0.001^{*}$ \\
\hline Short-stay service & 288 & 12.3 & 21,906 & 11.4 & $<0.001^{*}$ \\
\hline Facility service & 165 & 7.0 & 4513 & 2.3 & $<0.001^{*}$ \\
\hline
\end{tabular}

Footnote

LTCl long term care insurance, $S D$ standard deviation

* chi-squared test

${ }^{+}$Wilcoxon rank-sum test

${ }^{\ddagger}$ Include project eligible persons, exclude them from the chi-squared test

$\S$ exclude them from the chi-squared test

was lower than that of non-victims $(p<0.001)$. In contrast, among facility residents, that of victims was higher than that of non-victims $(p=0.003)$. Among facility residents, $36.7 \%$ of victims $(n=247)$ and $3.6 \%$ of non-victims $(n=3028)$ were transferred to different facilities after the disaster $(p<0.001)$.

Figure 2 shows the mean costs for LTCI services for the period from 2 months before to 6 months after the 
disaster. Victims in home residents and facility residents increased the cost after the disaster $(p<0.001)$. For the home victims, the increase in the mean cost converged within the observation period. On the other hand, for facility victims, the increase had not converged during the observation period.

Figure 3 shows the proportion of participants who used each LTCI service among home residents by month. Victims less used home-based services through all periods $(p<0.001)$. However, victims used more short-stay services until 2 months after the disaster $(p<0.001)$, and facility services for all months after the disaster $(p<0.001)$.

We showed the results of GEEs on total costs of LTCI and estimated AME on the LTCI costs of victims as the attributable costs from the disaster (Fig. 4, Supplementary Table 2 [see Supplementary File 2] and Supplementary Table 3 [see Supplementary File 3]). Among home residents and facility residents, the attributable costs of the disaster increased during all the months after the disaster. The attributable cost for home residents at 2 months after was $\$ 214$ (Standard Error (SE): 12, $p<0.001$ ), which was the highest through the observation period. In comparison, among facility residents, the attributable cost immediately after the disaster increased by up to $\$ 850$ (SE: $29, p<0.001$ ).

As with cost, we estimated AME on the service utilization of home victims as the attributable risk from the disaster (Fig. 5, Supplementary Table 4 [see Supplementary
File 4] and Supplementary Table 5 [see Supplementary File 5]). The AME of utilization for home-based service were lower among victims than non-victims from 2 months after the disaster. The lowest AME was -15.2\% (SE:1.3, $p<0.001)$ at 2 months after the disaster. On the other hand, the AME for short-stay service increased by up to $8.2 \%$ (SE: $0.9, p<0.001$ ) and the AME for the facility service increased by up to $7.4 \%$ (SE: $0.7, p<0.001$ ), respectively.

\section{Discussion}

The monthly total costs for LTCI services of victims increased regardless of the residential environment. Details of changes amongst home residents include: 1) an increase in short-stay services and facility services and 2) a decrease of home-based services. Similarly, the cost for facility-victims increased after the disaster. These changes gradually diminished after 6 months.

The monthly total cost for LTCI services among home residents increased by up to $\$ 213.60$ (SE: $13.3, p<0.001$ ) at 2 months after the disaster, and diminished gradually for a half-year, even though disuse months of LTCI services amongst victims were more than non-victims. After the GEJE, an ecological study showed that the total costs for LTCI services decreased in the affected area [30]. Earthquakes and a tidal waves cause extensive damage in a geographically consistent manner [45]. In comparison, areas impacted by floods were mainly

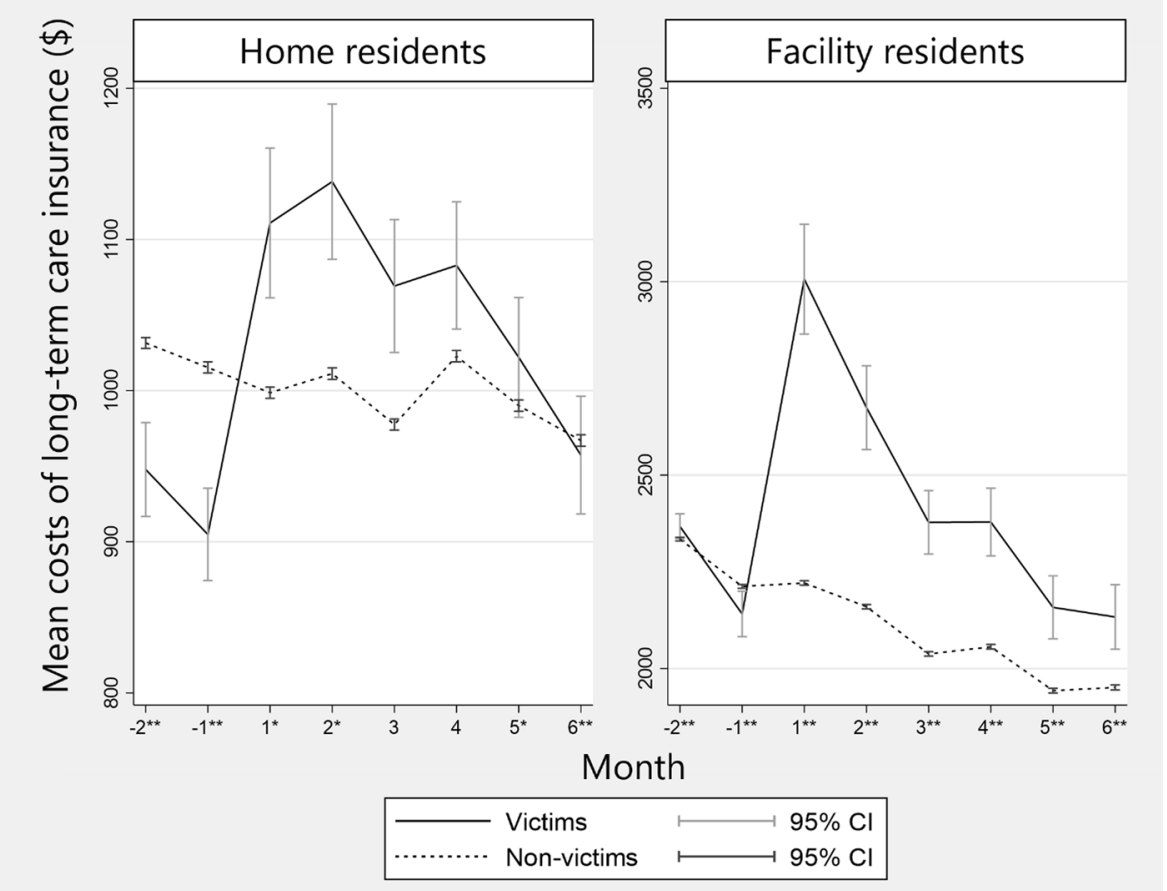

Fig. 2 Mean costs for long-term care insurance system. Footnote: *: $P$ value is $<0.05$ by Wilcoxon rank-sum test. **: $P$ value is $<0.001$ by Wilcoxon rank-sum test. Month: month from the 2018 Japan Floods. Cl: confidence interval 

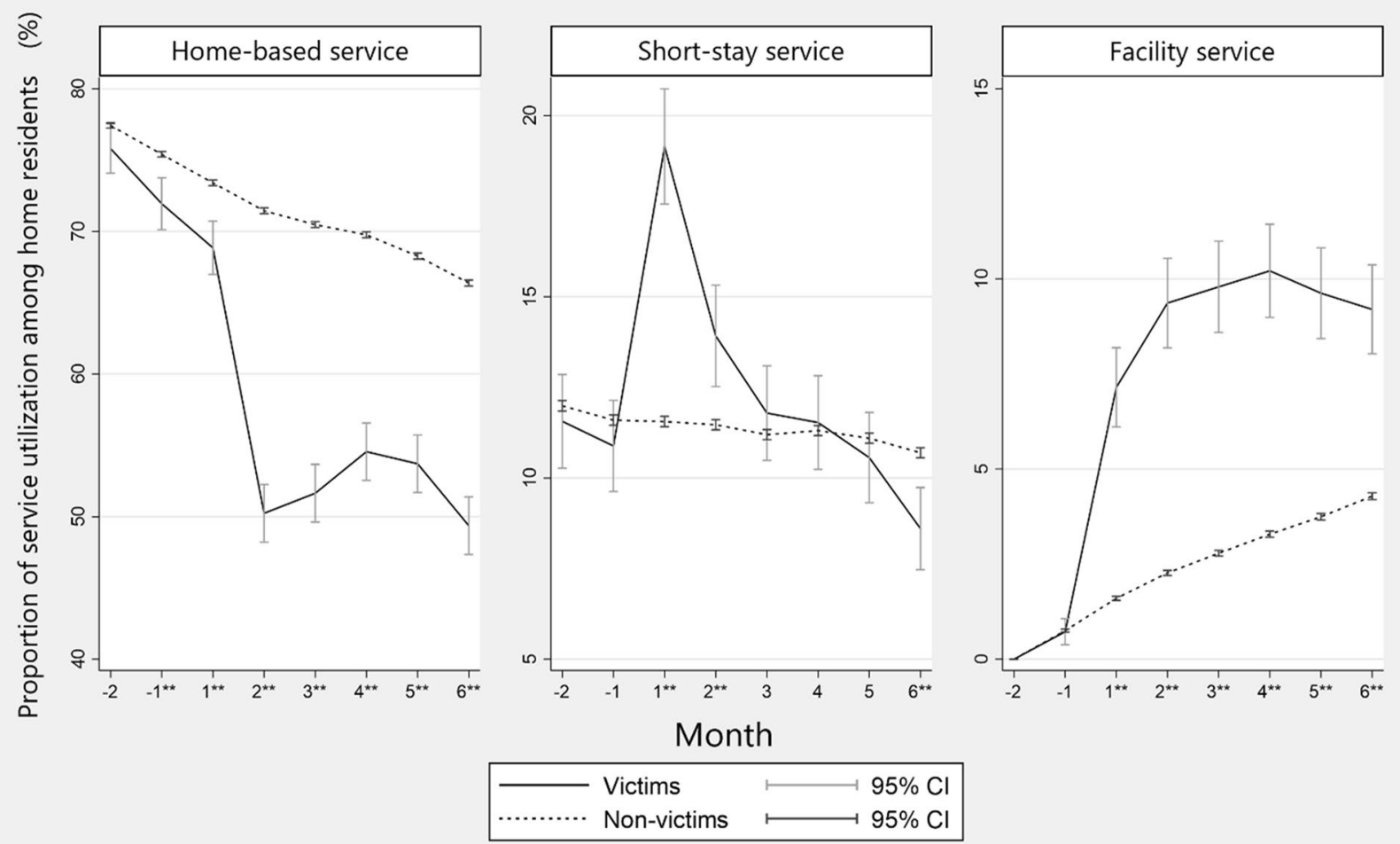

Fig. 3 Proportion of service utilization among home residents. Footnote: **: P value is $<0.001$ by Wilcoxon rank-sum test. Month: month from the 2018 Japan Floods. Cl: confidence interval

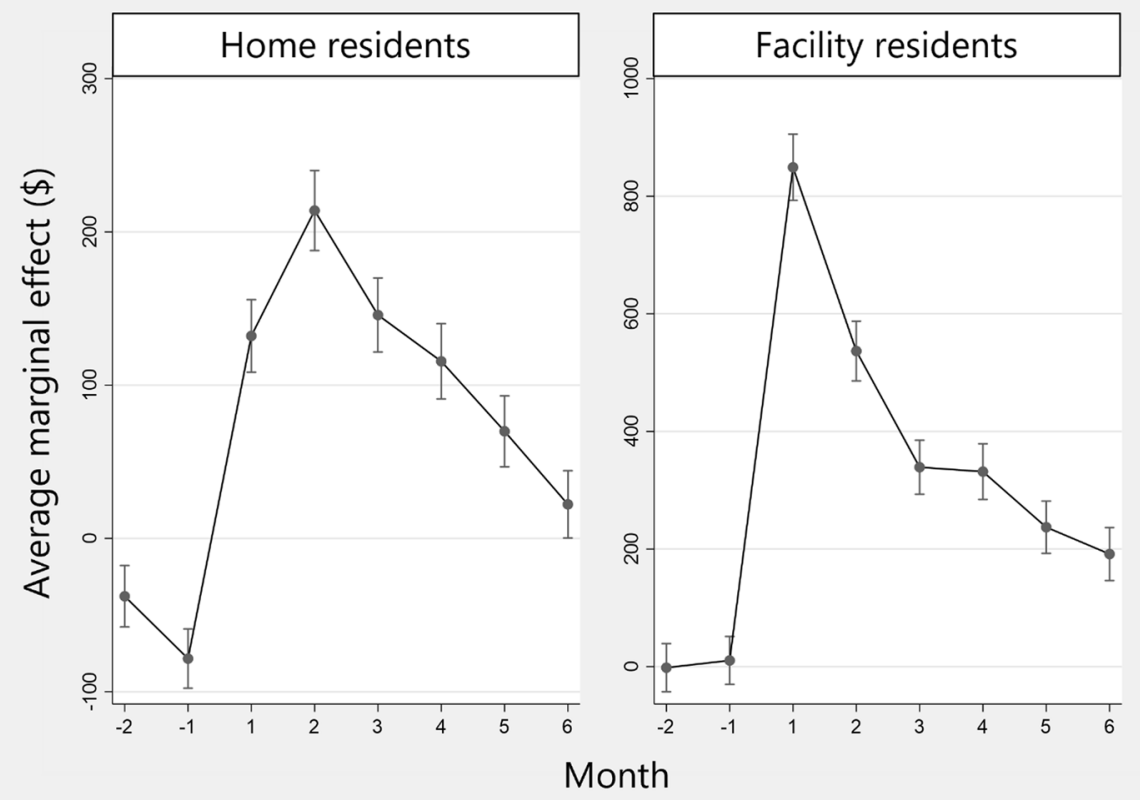

Fig. 4 Average marginal effect on long-term care insurance costs of victims as the attributable costs from the disaster from the results of generalized estimating equations. Footnote: Average marginal effect on the utilization of the long-term care insurance costs of victims is the attributable cost due to the 2018 Japan Floods. We estimated the average marginal effect from the result of generalized estimating equations 


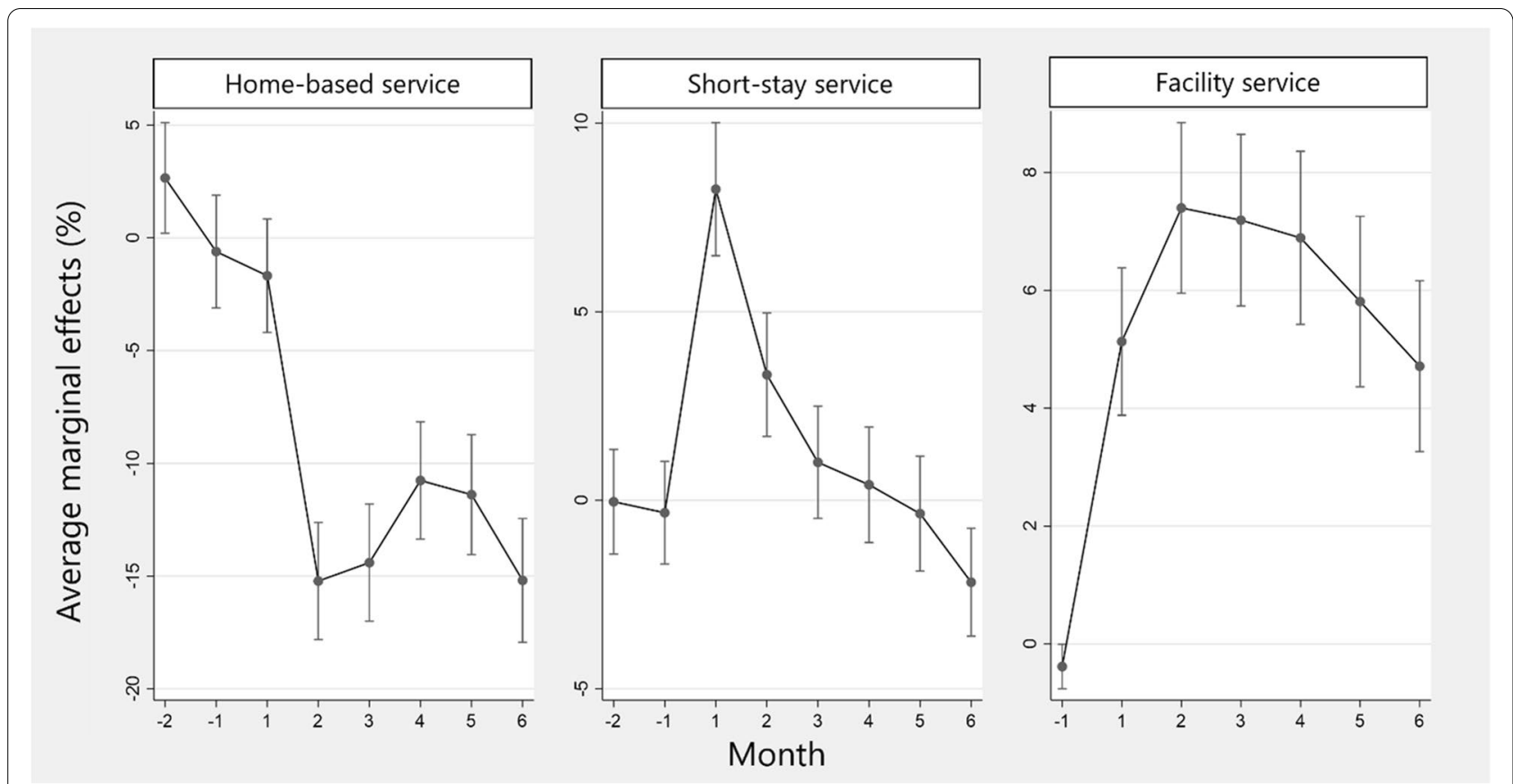

Fig. 5 Average marginal effect on the utilization of long-term care insurance services of victims among home residents. Footnote: Average marginal effects on the utilization of long-term care insurance services of victims among home residents is the attributable relative risk due to the 2018 Japan Floods. We estimated the average marginal effect from the result of generalized estimating equations

near rivers or along slopes and unaffected areas were mixed even in the same municipality [46]. LTCI services in an unaffected area could complement services in an affected area where services become unavailable. Therefore, the duration of a full stop in the supply of LTCI services may be short. Increases in LTCI service use would have been supported by undamaged facilities or services. However, we cannot prove that such care needs truly arose caused by the disaster because the definition of victims was based on policy [34]. Since this policy gave affected people economic incentives, they might have been encouraged to use more LTCI services than nonvictims and this should be considered when interpreting the results of this study.

Victims who had been using home-care services increased the utilization of short-stay services and facility services after the disaster. The highest AME of short-stay service was $8.2 \%$ (SE: $0.9, p<0.001$ ) and that of facility services increased up to $7.4 \%$ (SE: 0.7 , $p<0.001)$. These victims and their families likely choose emergent use of these services because it was difficult to receive care at common shelters and the disaster decreased a family's ability to provide care [47]. MHLW announced the abolition of the upper limit in use of short-stay services for the evacuation [48]. This announcement would encourage more use of shortstay services. To adapt to emergencies, facilities in disaster hazard zones should plan for a modifiable fixed number in accordance with the scale of the disaster to accept vulnerable victims. Meanwhile, health issues continue to require study for victims evacuated to LTCI facilities as few studies have examined such services in care facilities. Past studies showed that elderly persons evacuated to shelters had lower health outcomes including a higher mortality rate [49-51]. However, in evacuation to LTCI facilities, they may receive needed essential care. This could prevent their health decline, such as ADL and quality of life. Accordingly, prognosis should be examined in future studies. Based on the results here, the local government and service providers should organize facility allocation and estimate a fixed number of added patients that can be admitted to each facility in an emergency during future disasters.

Among home residents, the AME of home-based service continued to decrease from 2 months after the disaster, and the lowest AME was $-15.2 \%$ (SE: $1.3, p<0.001$ ). Since the beginning of the month when the disaster occurred was still before the actual damage, the utilization of home-based services of the first month would not have declined. This decline was caused by the disruption of transportation networks or utilities [10]. Because the disruption could have decreased home care capabilities, the use of short-stay services and facility services might have increased. After being admitted to a facility, it is often difficult to return elderly patients back home [52]. This situation delayed the recovery of home-based services. 
The cost for facility-victims immediately increased after the disaster by $\$ 850.30$ (SE: $28.8, p<0.001$ ) and gradually diminished over 6 months. An increase of facility-victims would represent evacuation to different facilities. Because of the emergency, some refugees were changed from a multi-bedroom to a private room. In addition, MHLW announced a special provision, which could claim the cost for a private room when multiple refugees used a single room together as a multi-bedroom [53]. This would cause an increase in the cost for facility-victims. Facility-victims who were usually at a low ADL level or cognitive function find it difficult to use common shelters. Accordingly, they had to evacuate to other facilities. In the GEJE, short- and long-term mortality increased among facility-victims that evacuated to different facilities [51]. This may have been due to a lack of readiness on the part of shelters to deal with victims as well as fragmentation from previous care providers [51]. Upon a disaster, the decision of whether facility-victims need to evacuate should be made considering usable resources [54].

This was the first study to examine the attributable cost of the 2018 Japan Floods on long-term care, using LTCI claim data that covered all LTCI service users. The LTCI comprehensive database reflects a public insurance system and covers almost all persons in Japan aged over 65 years old. Therefore, this study examined the overall effect of the disaster on LTCI system. The database is highly accurate as it is managed by the national government. The results of this study can estimate the elevated costs of LTCI and the change in service utilization of LTCI chronologically per the magnitude of the torrential rains and floods or the number of the victims. Based on this study, the government needs to plan care for the elderly as early as possible and respond quickly after a disaster occurs. Moreover, local government and service providers should organize facility allocation to prepare for a disaster and estimate a capacity for an emergency.

This study has several limitations. First, the LTCI database rarely has information about death and medical attendance, such as diseases, treatment and admission. Although there is no information in this database, we evaluated the quantitative changes in the costs and service utilization of LTCI as the population average using the GEEs. To estimate the effect of LTCI, this study could show the results with available resources. Moreover, since this database started to contain the information to link the National Database of Health Insurance Claims from March 2020, the study integrated both databases can be organized hereafter. Second, although we defined "victims" as LTCI service users who were exempted from out-of-pocket expenses after the disaster, some other persons were also given relief from out-ofpocket payments due to the disaster. However, we could not distinguish such persons from non-victims. Therefore, we risk underestimating the effect of the disaster. Third, the results of this study did not include the cost of informal care and resources which was not covered by LTCI system. As a future study, it is also important to investigate a specific population among victims and capture changes in informal care. Moreover, facility residents were fewer in victims. Generally, facility residents are older and more vulnerable than home residents. The risk of flooding and its adverse health impacts are unevenly distributed [15]. Because most facilities are built in areas less prone to natural disasters, the 2018 Japan Floods damaged mainly private homes and home residents. A similar trend is likely in future torrential rains and floods.

\section{Conclusions}

The 2018 Japan Floods increased LTCI service costs for victims regardless of the residential environment. The increase gradually diminished over half-a-year. Considering the increased costs and utilization of care facilities according to the disaster scale, local governments and care providers should prepare for future floods and other emergencies.

\section{Abbreviations \\ AME: Average marginal effects; ADL: Activity of daily living; GEE: Generalized estimating equation; GEJE: Great East Japan Earthquake; LTCI: Long-term care insurance; MHLW: Ministry of Health, Labour and Welfare; SE: Standard error; WHO: World Health Organization.}

\section{Supplementary Information}

The online version contains supplementary material available at https://doi. org/10.1186/s12889-022-12492-7.

Additional file 1: Supplementary Table 1. Service Classification Codes (service-kubun-code).

Additional file 2: Supplementary Table 2. Results of Generalized Estimating Equations on Total Costs of Long-term Care Insurance System.

Additional file 3: Supplementary Table 3. Average Marginal Effect on Long-term Care Insurance Costs of Victims as Attributable Costs from the Disaster (\$).

Additional file 4: Supplementary Table 4. Results of Generalized Estimating Equations on Service Utilization of Long-term Care Insurance System.

Additional file 5: Supplementary Table 5. Average Marginal Effects on Utilization of Long-term Care Insurance Services of Victims Among Home Residents (\%).

\section{Acknowledgements}

Not applicable.

\section{Authors' contributions}

SY contributed to study concept, design, acquisition of data, analysis, interpretation of data and drafting of the manuscript. SaK contributed to analysis, interpretation of data and critical revision of the manuscript for important intellectual content. SI and SoK contributed to critical revision of the manuscript for important intellectual content. MM contributed to study concept, 
design, acquisition of data, drafting of the manuscript and critical revision of the manuscript for important intellectual content. The authors read and approved the final manuscript.

\section{Funding}

This study is funded by the Ministry of Education, Culture, Sports, Science and Technology KAKENHI Grant-in-Aid for Young Scientists, grant number (19K19388).

\section{Availability of data and materials}

The data that support the findings of this study are available from the Ministry of Health, Labour and Welfare, but restrictions apply to the availability of these data, which were used under license for the current study, and so are not publicly available. Data are however available from the authors upon reasonable request and with permission of the Ministry of Health, Labour and Welfare.

\section{Declarations}

\section{Ethics approval and consent to participate}

Ethical approval was granted by the Ethics Committee for Epidemiological Research at Hiroshima University (Ref. no. E-1389). The study was conducted according to the Declaration of Helsinki. The need to obtain informed consent from each subject was waived as this was a retrospective review of the subjects' records according to the Ethical Guidelines for Medical and Health Research Involving Human Subjects in Japan. The name of the ethics committee that waived the requirement of informed consent was the Ethics Committee for Epidemiological Research at Hiroshima University.

\section{Consent for publication}

Not applicable.

\section{Competing interests}

The authors declare that they have no competing interests.

\section{Author details}

'Department of Community-Based Medical System, Graduate School of Biomedical and Health Sciences, Hiroshima University, 1-2-3 Kasumi, Minami-ku, Hiroshima-ken, Hiroshima-shi 734-8551, Japan. ${ }^{2}$ Environmental Health Sciences Laboratory, Graduate School of Advanced Science and Engineering, Hiroshima University, 1-3-2 Kagamiyama, Hiroshima-ken, Higashi-Hiroshima-shi, Japan. ${ }^{3}$ Department of Medicine for Integrated Approach to Social Inclusion, Graduate School of Biomedical and Health Sciences, Hiroshima University, Hiroshima, Japan. ${ }^{4}$ Division of Health Policy and Management, Center for Community Medicine, Jichi Medical University, 3311-1 Yakushiji, Tochigi-ken, Shimotsuke-shi 329-0498, Japan.

\section{Received: 1 October 2021 Accepted: 31 December 2021}

Published online: 17 February 2022

\section{References}

1. Costello A, Abbas M, Allen A, Ball S, Bell S, Bellamy R, et al. Managing the health effects of climate change: lancet and University College London Institute for Global Health Commission. Lancet. 2009;373(9676):1693-733.

2. Organization WH: Quantitative risk assessment of the effects of climate change on selected causes of death, 2030s and 2050s. 2014.

3. Watts N, Amann M, Arnell N, Ayeb-Karlsson S, Beagley J, Belesova K, et al. The 2020 report of the lancet countdown on health and climate change: responding to converging crises. Lancet. 2021;397(10269):129-70.

4. Organization WH: Protecting health from climate change: Global research priorities 2009.

5. Shimpo A, Takemura K, Wakamatsu S, Togawa H, Mochizuki Y, Takekawa M, Tanaka S, Yamashita K, Maeda S, Kurora R et al: Primary Factors behind the Heavy Rain Event of July 2018 and the Subsequent Heat Wave in Japan. SOLA. 2019;15A:13-18. https://doi.org/10.2151/sola.15A-003.

6. Tsuguti H, Seino N, Kawase H, Imada Y, Nakaegawa T, Takayabu I. Meteorological overview and mesoscale characteristics of the heavy rain event of July 2018 in Japan. Landslides. 2019;16(2):363-71.
7. Japan Meteorological Agency. About the Name of the Heavy Rain, Japan Meteorological Agency (in Japanese) https://www.jma.go.jp/jma/press/ 1807/09b/20180709_meishou.pdf. Accessed 8 Sept 2021.

8. Ohara M, Nagumo N. Mortality by age group and municipality in the July 2018 torrential rainfall. J Disaster Res. 2019;14(6):912-21.

9. Cabinet Office. Damage caused by the July 2018 torrential rainstorm. http://www.bousai.go.jp/updates/h30typhoon7/pdf/310109_1700_ h30typhoon7_01.pdf. Accessed 26 Sept 2021.

10. Chugoku Regional Development Bureau. Torrential rainfall in July 2018: Record of disaster response, Chugoku Regional Development Bureau. https://www.cgr.mlit.go.jp/photo/h3007gouu_kiroku/pdf/h3007gouu_ kiroku_all.pdf.

11. West Japan Torrential Damage of $1,940.0$ Billion Yen, Asahi Shimbun (2018 September 28) (in Japanese). Available from: https://www.asahi.com/artic les/ASL9X54P7L9XUTIL036.html. Accessed 26 Sept 2021.

12. Ichiseki H. Features of disaster-related deaths after the great East Japan earthquake. Lancet. 2013;381(9862):204.

13. Roy N, Thakkar P, Shah H. Developing-world disaster research: present evidence and future priorities. Disaster Med Public Health Prep. 2011;5(2):112-6.

14. Trombley J, Chalupka S, Anderko L. Climate change and mental health. Am J Nurs. 2017;117(4):44-52.

15. Paavola J. Health impacts of climate change and health and social inequalities in the UK. Environ Health. 2017;16(1):113.

16. Liu LY, Wu WN, McEntire DA. Six Cs of pandemic emergency management: a case study of Taiwan's initial response to the COVID-19 pandemic. Int J Disaster Risk Reduct. 2021;64:102516.

17. Pathak S, Ahmad MM. Flood risk reduction through insurance for SMEs in Pathumthani province, Thailand. Dev Pract. 2018;28(2):303-10.

18. Pathak S, Ahmad MM. Flood recovery capacities of the manufacturing SMEs from floods: a case study in Pathumthani province, Thailand. Int J Disaster Risk Reduct. 2016;18:197-205.

19. Pekovic $V$, Seff $L$, Rothman M. Planning for and responding to special needs of elders in natural disasters. Generations. 2007;31(4):37-41.

20. Yoshida S, Kashima S, Matsumoto M. The effect of the 2018 Japan floods on cognitive decline among long-term care insurance users in Japan: a retrospective cohort study. Environ Health Prev Med. 2021;26(1):113.

21. Wakui T, Agree EM, Saito T, Kai I. Disaster preparedness among older Japanese adults with long-term care needs and their family caregivers. Disaster Med Public Health Prep. 2017;11(1):31-8.

22. Logue JN, Hansen H, Struening E. Some indications of the long-term health effects of a natural disaster. Public Health Rep. 1981;96(1):67-79.

23. Koike S, Furui Y. Long-term care-service use and increases in care-need level among home-based elderly people in a Japanese urban area. Health Policy. 2013;110(1):94-100.

24. Tamiya N, Noguchi H, Nishi A, Reich MR, Ikegami N, Hashimoto H, et al. Population ageing and wellbeing: lessons from Japan's long-term care insurance policy. Lancet. 2011;378(9797):1183-92.

25. Ministry of Health, Labor and Welfare of Japan. Long-term Care Insurance in Japan. https://www.mhlw.go.jp/english/topics/elderly/care/index. html. Accessed 26 Sept 2021.

26. Ministry of Health, Labour and Welfare. The Long-term care Insurance System. https://www.mhlw.go.jp/english/topics/elderly/care/2.html. Accessed 24 Nov 2021.

27. Ministry of Health, Labor and Welfare of Japan. Long-term Care Insurance system of Japan. https://www.mhlw.go.jp/english/policy/care-welfare/ care-welfare-elderly/dl/Itcisj_e.pdf. Accessesed 24 Nov 2021.

28. Morita T, Ando M, Ohtsu Y. Mass evacuation and increases in long-term care benefits: lessons from the Fukushima nuclear disaster. PLoS One. 2019;14(9):e0218835.

29. Inoue $Y$, Jeong $S$. Did the number of older people requiring long-term care and expenditure increase after the 2011 great East Japan earthquake? Analysis of changes over six years. Int J Environ Res Public Health. 2020;17(5):1621.

30. Uchimura M, Kizuki M, Takano T, Morita A, Seino K. Impact of the 2011 great East Japan earthquake on community health: ecological time series on transient increase in indirect mortality and recovery of health and long-term-care system. J Epidemiol Community Health. 2014;68(9):874-82.

31. Zhong S, Yang L, Toloo S, Wang Z, Tong S, Sun X, et al. The long-term physical and psychological health impacts of flooding: a systematic mapping. Sci Total Environ. 2018;626:165-94. 
32. Ministry of Health, Labour and Welfare. Provision of Anonymous Care Information (in Japanese). https://www.mhlw.go.jp/stf/shingi2/00001 98094_00033.html. Accessed 24 Nov 2021.

33. Ministry of Health, Labor and Welfare. Report on long-term care insurance service status 2020. https://www.e-stat.go.jp/stat-search/file-downl oad?statlnfld=000031960956\&fileKind=0. Accessed 24 Nov 2021

34. Ministry of Health, Labor and Welfare. Handling of Partial Payment, etc for Victims of the 2018 Japan floods. https://www.mhlw.go.jp/content/ 10600000/000333842.pdf. Accessed 24 Nov 2021

35. Statistics of Japan. 2017 Long-Term Care Insurance Service Status Report: Table 19 User Burden Reduction/Exemption Certification by Prefecture (Heisei 29 nendo kaigo-jigyou-houkokusyo: dai 19 hyou todouhukenbetsu riyousya-hutan-gengaku-menjo-nintei). https://www.e-stat.go. jp/stat-search/file-download?statlnfld $=000031859843 \&$ fileKind $=0$. Accessed 26 Sept 2021

36. The Bank of Japan. Trading Conditions in the Tokyo Foreign Exchange Market during 2018 (in Japanese). https://www.boj.or.jp/statistics/market/forex/fxdaily/ex2018.pdf. Accessed 24 Nov 2021.

37. Dodd S, Bassi A, Bodger K, Williamson P. A comparison of multivariable regression models to analyse cost data. J Eval Clin Pract. 2006;12(1):76-86.

38. Rattinger GB, Sanders CL, Vernon E, Schwartz S, Behrens S, Lyketsos CG, et al. Neuropsychiatric symptoms in patients with dementia and the longitudinal costs of informal care in the Cache County population. Alzheimers Dement (N Y). 2019;5:81-8.

39. Ju Kim S, Han KT, Kim SJ, Park EC. Pay-for-performance reduces healthcare spending and improves quality of care: analysis of target and nontarget obstetrics and gynecology surgeries. Int J Qual Health Care. 2017;29(2):222-7.

40. Sopina E, Spackman E, Martikainen J, Waldemar G, Sørensen J. Long-term medical costs of Alzheimer's disease: matched cohort analysis. Eur J Health Econ. 2019;20(3):333-42.

41. Zhang J, Yu KF. What's the relative risk?A method of correcting the odds ratio in cohort studies of common outcomes. JAMA 1998;280(19):1690-1.

42. Yelland LN, Salter AB, Ryan P. Performance of the modified Poisson regression approach for estimating relative risks from clustered prospective data. Am J Epidemiol. 2011;174(8):984-92.

43. Janani L, Mansournia MA, Nourijeylani K, Mahmoodi M, Mohammad K. Statistical issues in estimation of adjusted risk ratio in prospective studies. Arch Iran Med. 2015;18(10):0-0.

44. Chen W, Shi J, Qian L, Azen SP. Comparison of robustness to outliers between robust poisson models and log-binomial models when estimating relative risks for common binary outcomes: a simulation study. BMC Med Res Methodol. 2014;14(1):82.

45. Ishigaki A, Higashi H, Sakamoto T, Shibahara S. The great East-Japan earthquake and devastating tsunami: an update and lessons from the past great earthquakes in Japan since 1923. Tohoku J Exp Med. 2013;229(4):287-99.

46. Houston D, Werrity A, Bassett D, Geddes A, Hoolachan A, McMillan M. Pluvial (rain-related) flooding in urban areas: the invisible hazard; 2011.

47. Cabinet Office. Guidelines for Securing and Operating Welfare Shelters. http://www.bousai.go.jp/taisaku/hinanjo/pdf/1604hinanjo_hukushi_ guideline.pdf. Accessed 26 Sept 2021.

48. Ministry of Health, Labor and Welfare. Treatment of cases in which the amount exceeded the Category Payment Limit due to use of short-stay service for evacuation due to July 2018 torrential rains. https://www. mhlw.go.jp/stf/newpage_00443.html. Accessed 26 Sept 2021.

49. Hasegawa A, Ohira T, Maeda M, Yasumura S, Tanigawa K. Emergency responses and health consequences after the Fukushima accident; Evacuation and Relocation. Clin Oncol (R Coll Radiol). 2016;28(4):237-44

50. National Institute for Land and Infrastructure Management. A guide to the materialization of evacuation support measures for persons in need of help in a disaster. http://www.nilim.go.jp/lab/bcg/siryou/tnn/tnn02 92pdf/ks0292.pdf. Accessed 26 Sept 2021.

51. Nomura S, Blangiardo M, Tsubokura M, Nishikawa Y, Gilmour S, Kami $M$, et al. Post-nuclear disaster evacuation and survival amongst elderly people in Fukushima: a comparative analysis between evacuees and non-evacuees. Prev Med. 2016;82:77-82.
52. Morita K, Ono S, Ishimaru M, Matsui H, Naruse T, Yasunaga H. Factors affecting discharge to home of geriatric intermediate care facility residents in Japan. J Am Geriatr Soc. 2018;66(4):728-34.

53. Ministry of Health, Labor and Welfare. Handling of Long-Term Care Insurance Fees, etc. for Disasters Related to the 2018 Japan floods. https:// www.mhlw.go.jp/content/12300000/000334950.pdf. Accessed 24 Nov 2021.

54. Dosa D, Hyer K, Thomas K, Swaminathan S, Feng Z, Brown L, et al. To evacuate or shelter in place: implications of universal hurricane evacuation policies on nursing home residents. J Am Med Dir Assoc. 2012;13(2):190. e191-7.

\section{Publisher's Note}

Springer Nature remains neutral with regard to jurisdictional claims in published maps and institutional affiliations.
Ready to submit your research? Choose BMC and benefit from:

- fast, convenient online submission

- thorough peer review by experienced researchers in your field

- rapid publication on acceptance

- support for research data, including large and complex data types

- gold Open Access which fosters wider collaboration and increased citations

- maximum visibility for your research: over $100 \mathrm{M}$ website views per year

At BMC, research is always in progress.

Learn more biomedcentral.com/submissions 